\title{
Multi-commodity Flow Port Supply Chain Network Model for Multi-criteria under Uncertainty \\ Haiyan Xie ${ }^{1, a}$, Lirui Xiao ${ }^{1, b}$ and Guoyan Chen ${ }^{1, c}$
}

\author{
${ }^{1}$ Department of Mathematics, Dalian Maritime University, Liaoning, Dalian 116026, China \\ awinteriscoming@sina.com, ${ }^{b} \mathrm{x} / \mathrm{r}$ _math@163.com, 'WZDLMU@163.com
}

Keywords: port supply chain; equilibrium model; multi-commodity flow; multicriteria decision-making; variational inequalities

\begin{abstract}
In this paper, we present a port supply chain network model with multiple tiers of decision makers, consisting, respectively, of suppliers, port agents and demanding market. First, we study the suppliers' multicriteria decision-making and market's demanding under uncertainty. And then we establish equilibrium of the members in port supply chain and set up the port supply chain network equilibrium model under condition of uncertainty of demanding, multi-commodity flow and multicriteria decision-making. Finally, a numerical example is given to show the rationality of our model by using MATLAB.
\end{abstract}

\section{Introduction}

Port supply chain is a system depended on the effective integration of multiple tiers of decision makers (including upstream and downstream suppliers, port agents and customers). Port (or port enterprise) as the center of a supply chain, using the system to transfer goods to the correct destination, makes sure the whole supply chain is low-cost and high-efficient. Scholars like Nagurney ${ }^{[1]}$, put forward the multi-criteria decision-making and comprehensive equilibrium model under stochastic demand by citing variational inequalities theory and equilibrium model, and study the balance of supply chain network. Dong Chen and Chen Guohua ${ }^{[2]}$,using variational inequalities as the chief analyzing means, establish supply chain network model for equilibrium under certainty and uncertainty. In addition, they get the root of variational inequalities by Quasi-Newton Methods.

Information sharing research has continued for some decades. But most of the articles are focus on product supply chain, rarely articles are focus on other field (especially on port supply chain) ${ }^{[3]}$. At the same time, domestic study of port supply chain network put emphases on the innovation of its structure, function and pattern, thence the study of inter-organizational relationships among port actors and others players of the supply chain are still weak.

This paper attempts to consider the present situation and structure in the port supply chain, and under the condition of uncertainty of demanding, sets up a a port supply chain network model with the feature of multilayer, multi-criteria decision-making, multi-commodity flow, and competitiveness running parallel to cooperation. Firstly, based on equilibrium model and variational inequalities, we analyze the balance requirement of decision makers, consisting of suppliers, port agents and demanding market. Then according to the requirement, we build the port supply chain network equilibrium model under condition of multi-commodity flow and multi-criteria decision-making. Finally, the rationality and validity of the model could be tested by citing an example.

\section{Problem Description}

Before modeling, we assume that each member in the port supply chain are rational economic man, is the pursuit of self-interest maximization, and members competing with each other, the cooperation between members of different layers. At the same time ,we assume that the network has $m$ suppliers, $n$ port agents and $l$ kinds of goods. 
Equilibrium Conditions of Suppliers. $q_{i}^{s}$ represents the quantities of goods $s$ which is provided by the supplier $i$, and $q^{s} \in R^{m}$ denotes the quantities of goods $s$ provided by m-suppliers, that is $q^{s}=\left(q_{1}^{s}, \cdots, q_{i}^{s}, \cdots, q_{m}^{s}\right)^{T}$. Let $q_{i j}^{s}$ represent the quantities of good $s$ provided by supplier $i$ to port agents $j$, therefore $Q^{s} \in R^{m \times n}$ denotes the full volume of business between m-suppliers and n-port agents about good $s$, that is $Q^{s}=\left(Q_{1}^{s}, \cdots, Q_{i}^{s}, \cdots, Q_{m}^{s}\right)^{T}$, in which $Q_{i}^{s}=\left(q_{i 1}^{s}, \cdots, q_{i j}^{s}, \cdots, q_{i n}^{s}\right)^{T} \cdot p_{i j}^{s}$ denotes the price of good $s$ which is provided by supplier $i$ to port agents $j$, called supply price. $f_{i}^{s}$ denotes the cost function of supplier $i$ for providing goods $s$. The cost of good $s$ provided by supplier $i$ are related to its quantities in all suppliers, therefore $f_{i}^{s}=f_{i}^{s}\left(q^{s}\right), \forall i \in\{1, \ldots, m\}, \forall s \in\{1, \ldots, l\} . c_{i j}^{s}$ denotes the transaction cost function about goods $s$ between supplier $i$ and port agents $j$.Because the transaction cost is related to the volume of business, we have function $c_{i j}^{s}$ for all $q_{i j}^{s}$, that is $c_{i j}^{s}=c_{i j}^{s}\left(q_{i j}^{s}\right), \forall i \in\{1, \ldots, m\}, \forall j \in\{1, \ldots, n\}$, $\forall s \in\{1, \ldots, l\}$.

As for suppliers, except for seeking the maximal profit, they should also consider maximizing the quantity to earn as much market share as possible. For every supplier, by weighting every target function, the suppliers' multi-criteria decision-making is as follow:

$\max \quad D_{i}=\sum_{s=1}^{l} \sum_{j=1}^{n} p_{i j}{ }^{s} q_{i j}{ }^{s}-\sum_{s=1}^{l} f_{i}^{s}\left(q^{s}\right)-\sum_{s=1}^{l} \sum_{j=1}^{n} c_{i j}{ }^{s}\left(q_{i j}{ }^{s}\right)+\alpha_{i} \sum_{s=1}^{l} \sum_{j=1}^{n} q_{i j}$

s.t. $\quad q_{i j}^{s} \geq 0, \forall i, j, s$

If cost function and transaction function both are continuous and differentiable convex function, then (1) is equivalent to the variational inequalities below, that is solving $\left(q^{s^{*}}, Q^{s^{*}}\right) \in K$, for $\forall\left(q^{s}, Q^{s}\right) \in K$, satisfying:

$$
\sum_{i=1}^{m}\left\{\sum_{s=1}^{l}\left[\frac{\partial f_{i}^{s}\left(q^{s^{*}}\right)}{\partial q_{i}^{s}}\right] \times\left(q_{i}^{s}-q_{i}^{s^{*}}\right)+\sum_{j=1}^{n} \sum_{s=1}^{l}\left[\frac{\partial c_{i j}^{s}\left(q_{i j}^{s^{*}}\right)}{\partial q_{i j}^{s}}-p_{i j}^{s}-\alpha_{i}\right] \times\left(q_{i j}^{s}-q_{i j}^{s^{*}}\right)\right\} \geq 0
$$

When the network comes to the equilibrium point, $q^{s^{*}}$ is equivalent to $Q^{s^{*}}$, and $\sum_{j=1}^{n} q_{i j}^{s}=q_{i}^{s}$. After moving and change the terms about without making the inequality untrue, we have:

$$
\sum_{i=1}^{m} \sum_{j=1}^{n} \sum_{s=1}^{l}\left(\frac{\partial c_{i j}^{s}\left(q_{i j}^{s^{*}}\right)}{\partial q_{i j}^{s}}-p_{i j}^{s}+\frac{\partial f_{i}^{s}\left(Q^{s^{*}}\right)}{\partial q_{i j}^{s}}-\alpha_{i}\right) \times\left(q_{i j}^{s}-q_{i j}^{s^{*}}\right) \geq 0
$$

Equilibrium Requirement of Port Agents. Retail price, denoted by $p_{j}^{s}$, is the price of goods $s$ provided by port agent $j$ to clients. $c_{j}^{s}$ denotes the expenditure port agent $j$ dealt with suppliers, because the cost is relevant to volume of business, we have $c_{j}^{s}=c_{j}^{s}\left(\sum_{i=1}^{m} q_{i j}^{s}\right)=c_{j}^{s}\left(Q^{s}\right), \forall j \in\{1, \ldots, n\}$.

Because the demand in consumer market is uncertain, we let $d_{j}^{s}\left(p_{j}^{s}\right)$ denote quantity demanded where port agent $j$ sells good $s$ with price $p_{j}^{s}$. According to demand rule, quantity demanded is inversely proportional to the price. Let $\varphi_{j}\left(x, p_{j}^{s}\right)$ denote density function of $d_{j}^{s}\left(p_{j}^{s}\right)$, and it is relevant to quantity demanded and price. $P_{j}$ denotes probability distribution function of $d_{j}^{s}\left(p_{j}^{s}\right)$, we have $\quad P_{j}\left(x, p_{j}^{s}\right)=P_{j}\left(d_{j}^{s} \leq x\right)=\int_{0}^{x} \varphi_{j}\left(x, p_{j}^{s}\right) d x$. And $q_{j}^{s}$ denotes the amount of good $s$ port agent $j$ got from all suppliers. The volume of business about good $s$ port agent $j$ had with clients can not 
exceed $\min \left\{q_{j}^{s}, d_{j}^{s}\right\}$, let $\Delta_{j}^{+}=\max \left\{0, q_{j}^{s}-d_{j}^{s}\right\}, \Delta_{j}^{-}=\max \left\{0, d_{j}^{s}-q_{j}^{s}\right\}, e_{j}^{+}$and $e_{j}^{-}$denote respectively the expectation of $\Delta_{j}^{+}$and $\Delta_{j}^{-}$as follows:

When supply exceeds demand, $e_{j}^{+} \equiv E\left(\Delta_{j}^{+}\right)=\int_{0}^{q_{j}^{s}}\left(q_{j}^{s}-x\right) \varphi_{j}\left(x, p_{j}^{s}\right) d x$

When demand exceeds supply, $e_{j}^{-} \equiv E\left(\Delta_{j}^{-}\right)=\int_{q_{j}^{s}}^{\infty}\left(x-q_{j}^{s}\right) \varphi_{j}\left(x, p_{j}^{s}\right) d x$

We introduce unit penalty variable $\lambda_{j}^{+}$and $\lambda_{j}^{-}$, then the expectation of port agent's total penalty is

$$
E\left(\lambda_{j}^{+} \Delta_{j}^{+}+\lambda_{j}^{-} \Delta_{j}^{-}\right)=\lambda_{j}^{+} e_{j}^{+}\left(q_{j}^{s}, p_{j}^{s}\right)+\lambda_{j}^{-} e_{j}^{-}\left(q_{j}^{s}, p_{j}^{s}\right)
$$

Expected revenue of port agent is $E\left(p_{j}^{s} \times \min \left\{q_{j}^{s}, d_{j}^{s}\right\}\right)$, according to $\min \left\{q_{j}^{s}, d_{j}^{s}\right\}=d_{j}^{s}-\Delta_{j}^{-}$, port agents have the optimization method:

$$
\max D_{j}=\sum_{s=1}^{l}\left\{p_{j}^{s} \times \hat{d}_{j}^{s}-\left(p_{j}^{s}+\lambda_{j}^{-}\right) e_{j}^{-}-\lambda_{j}^{+} e_{j}^{+}-c_{j}^{s}\left(Q^{s}\right)-\sum_{i=1}^{m} p_{i j}^{s} q_{i j}^{s}\right\}
$$

s.t. $\quad q_{i j}^{s} \geq 0, \forall i, s$

where $E\left(d_{j}^{s}\right)=\hat{d}_{j}^{s}$.A variational inequality method equivalent to the problem above is solving $Q^{s^{*}} \in R^{\mathrm{m} \times n}$ for $\forall Q^{s} \in R^{m \times n}$, satisfying:

$$
\sum_{i=1}^{m} \sum_{j=1}^{n} \sum_{s=1}^{l}\left[\lambda_{j}^{+} P_{j}\left(\sum_{i=1}^{m} q_{i j}^{s^{*}}, p_{j}^{s}\right)-\left(\lambda_{j}^{-}+p_{j}^{s}\right)\left(1-P_{j}\left(\sum_{i=1}^{m} q_{i j}^{s^{*}}, p_{j}^{s}\right)\right)+\frac{\partial c_{j}^{s}\left(Q^{s^{*}}\right)}{\partial q_{i j}^{s}}+p_{i j}^{s}\right] \times\left(q_{i j}^{s}-q_{i j}^{s^{*}}\right) \geq 0
$$

Where $e_{j}^{+}\left(q_{j}^{s}, p_{j}^{s}\right)$ and $e_{j}^{-}\left(q_{j}^{s}, p_{j}^{s}\right)$ are derivatives of $q_{i j}^{s}{ }^{[1]}$, denoted by

$$
\begin{aligned}
& \frac{\partial e_{j}^{+}\left(q_{j}^{s}, p_{j}^{s}\right)}{\partial q_{i j}^{s}}=P_{j}\left(q_{j}^{s}, p_{j}^{s}\right)=P_{j}\left(\sum_{i=1}^{m} q_{i j}^{s}, p_{j}^{s}\right) \\
& \frac{\partial e_{j}^{-}\left(q_{j}^{s}, p_{j}^{s}\right)}{\partial q_{i j}^{s}}=P_{j}\left(q_{j}^{s}, p_{j}^{s}\right)-1=P_{j}\left(\sum_{i=1}^{m} q_{i j}^{s}, p_{j}^{s}\right)-1
\end{aligned}
$$

Equilibrium Requirement of Demanding Market. When port agents and demanding market satisfy balance requirement, which is the random economic balance requirement seeing as an economic issue, we have

$$
\widehat{d_{j}^{s}}\left(p_{j}^{s^{*}}\right) \begin{cases}\leq \sum_{i=1}^{m} q_{i j}^{s^{*}}, \text { a.s } & p_{j}^{s^{*}}=0 \\ =\sum_{i=1}^{m} q_{i j}^{s^{*}}, \text { a.s } & p_{j}^{s^{*}}>0\end{cases}
$$

When $p_{j}^{s^{*}}>0$, the goods port agents bought from all the suppliers upstream are equal to its desired value of quantity demanded, that is supply-demand balance, $\hat{d}_{j}^{s}\left(p_{j}^{s^{*}}\right)=\sum_{i=1}^{m} q_{i j}^{s^{*}}$. Therefore, the balance problem is equivalent to the variational inequalities, that is finding $p_{j}^{s^{*}} \in R^{n}, \forall p^{s} \in R^{n}$, satisfying:

$$
\sum_{s=1}^{l} \sum_{j=1}^{n}\left(\sum_{i=1}^{m} q_{i j}^{s^{*}}-\hat{d}_{j}^{s}\left(p_{j}^{s^{*}}\right)\right) \times\left(p_{j}^{s}-p_{j}^{s^{*}}\right) \geq 0
$$

Where $p^{s}=\left\{p_{1}^{s}, \ldots \ldots, p_{n}^{s}\right\}$.

\section{Equilibrium Model of Port Supply Chain Network}

$\left(Q^{s^{*}}, p_{j}^{s^{*}}\right) \in R^{m \times n+n}$ is the expectation of port support chain network, if all of suppliers, port agents and demanding market satisfy their equilibrium requirement (3), (7) and (10). 
Theorem 1 Equilibrium requirement of multi-commodity flow port supply chain network model for multicriteria under uncertainty:

Solving $W^{*}=\left(Q^{s^{*}}, p_{j}^{s^{*}}\right) \in R^{m \times n+n}$, for $\forall\left(Q^{s}, p_{j}^{s}\right) \in R^{m \times n+n}$, satisfying:

$$
\begin{gathered}
\sum_{i=1}^{m} \sum_{j=1}^{n} \sum_{s=1}^{l}\left[\frac{\partial f_{i}^{s}\left(Q^{s^{*}}\right)}{\partial q_{i j}^{s}}+\frac{\partial c_{j}^{s}\left(Q^{s^{*}}\right)}{\partial q_{i j}^{s}}+\frac{\partial c_{i j}^{s}\left(q_{i j}^{s^{*}}\right)}{\partial q_{i j}^{s}}+\lambda_{j}^{+} P_{j}\left(\sum_{i=1}^{m} q_{i j}^{s^{*}}, p_{j}^{s^{*}}\right)\right. \\
\left.-\quad\left(\lambda_{j}^{-}+p_{j}^{s^{*}}\right)\left(1-P_{j}\left(\sum_{i=1}^{m} q_{i j}^{s^{*}}, p_{j}^{s^{*}}\right)\right)-\alpha_{i}\right] \times\left(q_{i j}^{s}-q_{i j}^{s^{*}}\right) \\
+\sum_{s=1}^{l} \sum_{j=1}^{n}\left(\sum_{i=1}^{m} q_{i j}^{s^{*}}-\hat{d}_{j}^{s}\left(p_{j}^{s^{*}}\right)\right) \times\left(p_{j}^{s}-p_{j}^{s^{*}}\right) \geq 0
\end{gathered}
$$

The inequality above is the sum of the variational inequalities (3), (7) and (10).

\section{Numerical Example}

To test the model, we generated a port supply chain network. Assume that two suppliers, two port agents and two goods are concluded in it. In the model we have three tiers, two endpoints are in the first two tiers, and two goods are circulating in it. To simplify the operation, let variable $\alpha_{i}=0.3$, $\lambda_{j}^{+}=\lambda_{j}^{-}=1$

Assume when agent $j$ sells good $s$ at the price of $p_{j}^{s}$, clients' demanding $d_{j}^{s}\left(p_{j}^{s}\right)$ is an uniform distribution on $\left[0, \frac{b_{j}}{p_{j}^{s}}\right]$, where $b_{j}=60$. From distribution function $P_{j}\left(x, p_{j}^{s}\right)=\int_{0}^{x} \varphi_{j}\left(x, p_{j}^{s}\right) d x$, we have $\varphi_{j}\left(x, p_{j}^{s}\right)=\frac{p_{j}^{s}}{b_{j}}$, and

$$
P_{j}\left(x, p_{j}^{s}\right)= \begin{cases}\frac{x p_{j}^{s}}{b_{j}}, & x \in\left[0, \frac{b_{j}}{p_{j}^{s}}\right] \\ 1, & x \in\left(\frac{b_{j}}{p_{j}^{s}},+\infty\right)\end{cases}
$$

At the same time, the desired value of quantity demanded is $\hat{d}_{j}^{s}\left(p_{j}^{s}\right)=\frac{1}{2} \frac{b_{j}}{p_{j}^{s}}, j=1,2, \quad s=1,2$.Decision variables: $q_{i j}^{s}, p_{j}^{s}, i=1,2,=1,2, s=1,2 . \quad f_{i}^{s}\left(Q^{s}\right)$ denotes the cost function of good $s$ provided by supplier $i$ : $f_{1}^{1}\left(Q^{1}\right)=5\left(q_{1}^{1}\right)^{2}+2 q_{1}^{1} q_{2}^{1}+2 q_{1}^{1}$, $f_{2}^{1}\left(Q^{1}\right)=4\left(q_{2}^{1}\right)^{2}+2 q_{1}^{1} q_{2}^{1}+2 q_{2}^{1}, f_{1}^{2}\left(Q^{2}\right)=6\left(q_{1}^{2}\right)^{2}+2 q_{1}^{2} q_{2}^{2}+2 q_{1}^{2}, \quad, \quad f_{2}^{2}\left(Q^{2}\right)=5\left(q_{2}^{2}\right)^{2}+2 q_{1}^{2} q_{2}^{2}+2 q_{2}^{2}$. where $q_{1}^{1}=q_{11}^{1}+q_{12}^{1}, q_{2}^{1}=q_{21}^{1}+q_{22}^{1}, q_{1}^{2}=q_{11}^{2}+q_{12}^{2}, q_{2}^{2}=q_{21}^{2}+q_{22}^{2} . c_{j}^{s}\left(Q^{s}\right)$ denotes the expenditure function of goods $\boldsymbol{S}$ provided by supplier $j$ :

$$
c_{1}^{1}\left(Q^{1}\right)=1.5\left(\sum_{i=1}^{2} q_{i 1}^{1}\right)^{2}, \quad c_{2}^{1}\left(Q^{1}\right)=2\left(\sum_{i=1}^{2} q_{i 2}^{1}\right)^{2}, c_{1}^{2}\left(Q^{2}\right)=3.5\left(\sum_{i=1}^{2} q_{i 1}^{2}\right)^{2}, \quad c_{2}^{2}\left(Q^{2}\right)=5\left(\sum_{i=1}^{2} q_{i 2}^{2}\right)^{2} .
$$

$c_{i j}^{s}\left(q_{i j}^{s}\right)$ denotes transaction cost function of goods s supplier $i$ had with port agent $j$ :

$$
\begin{aligned}
& c_{11}^{1}\left(q_{11}^{1}\right)=2\left(q_{11}^{1}\right)^{2}+5 q_{11}^{1}, \quad c_{12}^{1}\left(q_{12}^{1}\right)=1.25\left(q_{12}^{1}\right)^{2}+3.5 q_{12}^{1} \\
& c_{21}^{1}\left(q_{21}^{1}\right)=1.5\left(q_{21}^{1}\right)^{2}+3 q_{21}^{1}, \quad c_{22}^{1}\left(q_{22}^{1}\right)=2.5\left(q_{22}^{1}\right)^{2}+5 q_{22}^{1}
\end{aligned}
$$




$$
\begin{gathered}
c_{11}^{2}\left(q_{11}^{2}\right)=2\left(q_{11}^{2}\right)^{2}+5 q_{11}^{2}, \quad c_{12}^{2}\left(q_{12}^{2}\right)=2\left(q_{12}^{2}\right)^{2}+7 q_{12}^{2} \\
c_{21}^{2}\left(q_{21}^{2}\right)=3\left(q_{21}^{2}\right)^{2}+7 q_{21}^{2}, \quad c_{22}^{2}\left(q_{22}^{2}\right)=2.5\left(q_{22}^{2}\right)^{2}+5 q_{22}^{2}
\end{gathered}
$$

In this paper, with the help of the modified projection algorithm and using MATLAB R2009b,we give the numerical example. Table 3.1 shows the result.

\begin{tabular}{|c|c|c|}
\hline Iteration Times & $q_{i j}^{s^{*}}$ & $p_{j}^{s}$ \\
\hline 7736 & $\begin{array}{l}q_{11}^{1 *}=0.0255 q_{12}^{1 *}=0.6867 \\
q_{21}^{1 *}=0.7986 q_{22}^{1 *}=0.1021 \\
q_{11}^{2 *}=0.5453 q_{12}^{2 *}=0.0603 \\
q_{21}^{2 *}=0.1246 q_{22}^{2 *}=0.5615\end{array}$ & $\begin{array}{l}p_{1}^{1^{*}}=34.2626 \\
p_{2}^{1^{*}}=35.4396 \\
p_{1}^{2^{*}}=39.6474 \\
p_{2}^{2^{*}}=41.5639\end{array}$ \\
\hline 7734 & $\begin{array}{l}q_{11}^{1 *}=0.0255 q_{12}^{1 *}=0.6867 \\
q_{21}^{1 *}=0.7986 q_{22}^{1 *}=0.1021 \\
q_{11}^{2 *}=0.5453 q_{12}^{2 *}=0.0603 \\
q_{21}^{2 *}=0.1246 q_{22}^{2 *}=0.5615\end{array}$ & $\begin{array}{l}p_{1}^{1^{*}}=34.2676 \\
p_{2}^{1^{*}}=35.4398 \\
p_{1}^{2^{*}}=39.6509 \\
p_{2}^{2^{*}}=41.5632\end{array}$ \\
\hline 7533 & $\begin{array}{l}q_{11}^{1 *}=0.0255 q_{12}^{1 *}=0.6867 \\
q_{21}^{1 *}=0.7986 q_{22}^{1 *}=0.1021 \\
q_{11}^{2 *}=0.5453 q_{12}^{2 *}=0.0603 \\
q_{21}^{2 *}=0.1246 q_{22}^{2 *}=0.5615\end{array}$ & $\begin{array}{l}p_{1}^{1^{*}}=34.2608 \\
p_{2}^{1^{*}}=35.4379 \\
p_{1}^{2^{*}}=39.6463 \\
p_{2}^{2^{*}}=41.5635\end{array}$ \\
\hline 7725 & $\begin{array}{l}q_{11}^{1 *}=0.0256 q_{12}^{1 *}=0.6867 \\
q_{21}^{1 *}=0.7987 q_{22}^{1 *}=0.1021 \\
q_{11}^{2 *}=0.5453 q_{12}^{2 *}=0.0603 \\
q_{21}^{2 *}=0.1246 q_{22}^{2 *}=0.5615\end{array}$ & $\begin{array}{l}p_{1}^{1^{*}}=34.5629 \\
p_{2}^{1^{*}}=35.4822 \\
p_{1}^{2^{*}}=39.6398 \\
p_{2}^{2^{*}}=41.5632\end{array}$ \\
\hline
\end{tabular}

Table 1 Result of Equilibrium Quantities and Equilibrium Price

Obviously, $Q^{1}>Q^{2}, p_{1}^{1}<p_{1}^{2}, p_{2}^{1}<p_{2}^{2}$. From the equations above we can see, two suppliers both have less carrying charge and transaction cost of goods 1 than goods 2 , so they have higher trading volume of goods 1 than goods 2 , that is $Q^{1}>Q^{2}$. It is market rule that goods 2 has higher price than goods 1 , because of its higher trading volume. Therefore, the model we built is reasonable according to the analysis above.

\section{Summary}

This paper builds multi-commodity flow port supply chain network model for multicriteria under uncertainty. Every member in this network comes to equilibrium point, and gets equilibrium trading volume and equilibrium price. This model provides scientific basis for members in supply chain to make decisions, and makes them realize the benefit relationship between themselves and the whole network. What's more, closed cooperation is promoted, high efficient and ordered modern port supply chain is formed.

Simultaneously, there are still some problems, we should add some risk functions to make the model more practical in our further study. In the value numerical example, the market demanding function port agents faced is a uniform distribution function, it is an ideal situation. 


\section{Acknowledgments}

This work was financially supported by the Fundamental Research Funds for the Central Universities (No. 3132015160).

\section{References}

[1] Nagurney A, Yan H, Dong J, Zhang D. Multitiered supply chain network: multicriteria decision--making under uncertainty[J]. Annals of Operation Research, 2005(135): 155-178.

[2] Dong chen, Chen Guohua. A supply chain network equilibrium model[J]. Transportation Research, 2008(7): 23-27.

[3] Hu Xianwu, Teng Cunxian. Research on the dynamic supply chain network equilibrium simulation model[J]. Statistics and Decision,2009(22): 43-46.

[4] Shi Lirong. Construction and management of port supply chain[J]. Transportation Research, 2007(3): 35-36.

[5] Zang Xiuqing, Zhang Xiaomin. Study on the distribution of interest in the port supply chain[J]. Statistics and Decision, 2012(16): 45-48.

[6] Lu Yongming. The status quo and review of port supply chain management[J]. Reformation \& Strategy, 2009(11): 176-178. 